NBER WORKING PAPER SERIES

\title{
THIRTY YEARS OF PROSPECT THEORY IN ECONOMICS: A REVIEW AND ASSESSMENT
}

\author{
Nicholas C. Barberis \\ Working Paper 18621 \\ http://www.nber.org/papers/w18621
}

\section{NATIONAL BUREAU OF ECONOMIC RESEARCH 1050 Massachusetts Avenue Cambridge, MA 02138}

December 2012

I am grateful to David Autor, Botond Koszegi, John List, Ted O'Donoghue, Matthew Rabin, Andrei Shleifer, and Timothy Taylor for extensive comments on an early draft. The views expressed herein are those of the author and do not necessarily reflect the views of the National Bureau of Economic Research.

NBER working papers are circulated for discussion and comment purposes. They have not been peerreviewed or been subject to the review by the NBER Board of Directors that accompanies official NBER publications.

(C) 2012 by Nicholas C. Barberis. All rights reserved. Short sections of text, not to exceed two paragraphs, may be quoted without explicit permission provided that full credit, including $\odot$ notice, is given to the source. 
Thirty Years of Prospect Theory in Economics: A Review and Assessment

Nicholas C. Barberis

NBER Working Paper No. 18621

December 2012

JEL No. D03,D81,G02

\begin{abstract}
$\underline{\text { ABSTRACT }}$
Prospect theory, first described in a 1979 paper by Daniel Kahneman and Amos Tversky, is widely viewed as the best available description of how people evaluate risk in experimental settings. While the theory contains many remarkable insights, economists have found it challenging to apply these insights, and it is only recently that there has been real progress in doing so. In this paper, after first reviewing prospect theory and the difficulties inherent in applying it, I discuss some of this recent work. While it is too early to declare this research effort an unqualified success, the rapid progress of the last decade makes me optimistic that at least some of the insights of prospect theory will eventually find a permanent and significant place in mainstream economic analysis.
\end{abstract}

Nicholas C. Barberis

Yale School of Management

135 Prospect Street

P O Box 208200

New Haven, CT 06520-8200

and NBER

nick.barberis@yale.edu 
In 1979, two Israeli psychologists, Daniel Kahneman and Amos Tversky, already famous for their work on judgment heuristics, published a paper in the journal Econometrica titled “Prospect Theory: An Analysis of Decision under Risk.” The paper accomplished two things. It collected in one place a series of simple but compelling demonstrations that, in laboratory settings, people systematically violate the predictions of expected utility theory, economists’ workhorse model of decision-making under risk. It also presented a new model of risk attitudes called "prospect theory," which elegantly captured the experimental evidence on risk-taking, including the documented violations of expected utility.

More than 30 years later, prospect theory is still widely viewed as the best available description of how people evaluate risk in experimental settings. Kahneman and Tversky's papers on prospect theory have been cited tens of thousands of times and were decisive in the awarding to Kahneman, in 2002, of the Nobel Prize in economic sciences. (Tversky would surely have shared the prize had he not passed away in 1996 at the age of 59).

It is curious, then, that so many years after the publication of the 1979 paper, there are relatively few well-known and broadly accepted applications of prospect theory in economics. One might be tempted to conclude that, even if prospect theory is an excellent description of behavior in experimental settings, it is less relevant outside the laboratory. In my view, this lesson would be incorrect. Rather, the main reason that applying prospect theory in economics has taken so long is that, in a sense that I make precise in the next section, it is hard to know exactly how to apply it. While prospect theory contains many remarkable insights, it is not ready-made for economic applications.

Over the past decade, researchers in the field of behavioral economics have put a lot of thought into how prospect theory should be applied in economic settings. This effort is bearing fruit. A significant body of theoretical work now incorporates the ideas in prospect theory into more traditional models of economic behavior; and a growing body of empirical work tests the predictions of these new theories. In this essay, after first reviewing prospect theory and the difficulties inherent in applying it, I discuss some of 
this recent work. It is too early to declare this research effort an unqualified success, but the rapid progress of the last decade makes me optimistic that at least some of the insights of prospect theory will eventually find a permanent and significant place in mainstream economic analysis.

\section{Prospect Theory}

\section{The Model}

The original version of prospect theory is described in Kahneman and Tversky (1979). While this paper contains all of the theory’s essential insights, the specific model it proposes has some limitations: it can be applied to gambles with at most two non-zero outcomes, and it predicts that people will sometimes choose dominated gambles. In 1992, Kahneman and Tversky published a modified version of their theory known as “cumulative prospect theory” which resolves these problems. This version is the one typically used in economic analysis and it is the version I briefly review here.

Consider a gamble

$$
\left(x_{-m}, p_{-m} ; x_{-m+1}, p_{-m+1} ; \ldots ; x_{0}, p_{0} ; \ldots ; x_{n-1}, p_{n-1} ; x_{n}, p_{n}\right) \text {, }
$$

where the notation should be read as "gain $x_{-m}$ with probability $p_{-m}, x_{-m+1}$ with probability $p_{-m+1}$, and so on," where the outcomes are arranged in increasing order, so that $x_{i}<x_{j}$ for $i<j$, and where $x_{0}=0$. For example, a 50:50 bet to lose $\$ 100$ or gain $\$ 200$ would be expressed as $\left(-\$ 100, \frac{1}{2} ; \$ 200, \frac{1}{2}\right)$. Under expected utility theory, an individual evaluates the above gamble as

$$
\sum_{i=-m}^{n} p_{i} U\left(W+x_{i}\right)
$$

where $W$ is current wealth and $U(\cdot)$ is an increasing and concave utility function. Under cumulative prospect theory, by contrast, the gamble is evaluated as 


$$
\sum_{i=-m}^{n} \pi_{i} v\left(x_{i}\right)
$$

where $v(\cdot)$, the "value function," is an increasing function with $v(0)=0$, and where $\pi_{i}$ are "decision weights."

This formulation illustrates the four elements of prospect theory: 1) referencedependence, 2) loss aversion, 3) diminishing sensitivity, and 4) probability weighting. First, in prospect theory, people derive utility from gains and losses, measured relative to some reference point, rather than from absolute levels of wealth: the argument of $v(\cdot)$ is $x_{i}$, not $W+x_{i}$. Kahneman and Tversky motivate this assumption, known as "reference dependence," with explicit experimental evidence (see, for example, Problems 11 and 12 in their 1979 paper), but also by noting that our perceptual system works in a similar way: we are more attuned to changes in attributes such as brightness, loudness, and temperature than we are to their absolute magnitudes.

Second, the value function $v(\cdot)$ captures "loss aversion," the idea that people are much more sensitive to losses - even small losses -- than to gains of the same magnitude. Informally, loss aversion is generated by making the value function steeper in the region of losses than in the region of gains. This can be seen in Figure 1, which plots a typical value function; the horizontal axis represents the dollar gain or loss $x$, and the vertical axis, the value $v(x)$ assigned to that gain or loss. Notice that the value placed on a $\$ 100$ gain, $v(100)$, is smaller in absolute magnitude than $v(-100)$, the value placed on a $\$ 100$ loss. Kahneman and Tversky infer loss aversion from the fact that most people turn down the gamble ( $-\$ 100, \frac{1}{2} ; \$ 110, \frac{1}{2}$ ). As Rabin (2000) shows, it is very hard to understand this fact in the expected utility framework: the dollar amounts are so small relative to typical wealth levels that, under expected utility, the gamble is evaluated in a risk-neutral way; given its positive expected value, it is therefore attractive. For a loss averse individual,

\footnotetext{
${ }^{2}$ In taking $U(\cdot)$ to be increasing and concave and its argument to be the level of wealth, I am following the standard convention in applications of expected utility. The assumptions about the form of $U(\cdot)$ capture a simple intuition: that people prefer more wealth to less, and that an additional dollar has a smaller utility impact at higher wealth levels. The concavity assumption generates risk aversion: it predicts that people will prefer a gamble's expected value to the gamble itself.
} 
however, the gamble is unappealing: the pain of losing $\$ 100$ far outweighs the pleasure of winning \$110.

Third, as shown in Figure 1, the value function is concave in the region of gains but convex in the region of losses. This element of prospect theory is known as diminishing sensitivity because it implies that, while replacing a $\$ 100$ gain (or loss) by a $\$ 200$ gain (or loss) has a significant utility impact, replacing a \$1000 gain (or loss) by a $\$ 1100$ gain (or loss) has a smaller impact. The concavity over gains captures the finding that people tend to be risk averse over moderate probability gains: they typically prefer a certain gain of $\$ 500$ to a 50 percent chance of $\$ 1,000$. However, people also tend to be risk-seeking over losses: they prefer a 50 percent chance of losing $\$ 1,000$ to losing $\$ 500$ for sure. This motivates the convexity over losses. ${ }^{3}$

The fourth and final component of prospect theory is probability weighting. In prospect theory, people do not weight outcomes by their objective probabilities $p_{i}$, but rather, by transformed probabilities or decision weights $\pi_{i}$. The decision weights are computed with the help of a weighting function $w(\cdot)$ whose argument is an objective probability. The solid line in Figure 2 shows the weighting function proposed by Tversky and Kahneman (1992). As is visible in a comparison with the dotted line - a 45 degree line which corresponds to the expected utility benchmark -- the weighting function overweights low probabilities and underweights high probabilities.

In cumulative prospect theory, the weighting function is applied to cumulative probabilities - for example, to the probability of gaining at least $\$ 100$, or of losing $\$ 50$ or more. For the purposes of understanding the applications I describe later, the main thing the reader needs to know about probability weighting is that it leads the individual to overweight the tails of any distribution - in other words, to overweight unlikely extreme outcomes. Kahneman and Tversky infer this, in part, from the fact that people like both lotteries and insurance - they prefer a 0.001 chance of $\$ 5,000$ to a certain gain of $\$ 5$, but also prefer a certain loss of $\$ 5$ to a 0.001 chance of losing $\$ 5,000$ - a combination of behaviors that is difficult to explain with expected utility. Under cumulative prospect

\footnotetext{
${ }^{3}$ While the convexity of the value function over losses captures one important psychological intuition, it ignores another. An individual facing a loss that represents a large fraction of wealth will be very sensitive, not insensitive, to any additional losses. For some applications, it is important to take this into account.
} 
theory, the unlikely state of the world in which the individual gains or loses $\$ 5,000$ is overweighted in his mind, thereby explaining these choices. More broadly, the weighting function reflects the certainty equivalents people state for gambles that offer $\$ 100$, say, with probability $p$. For example, in an experimental study by Gonzalez and Wu (1999), subjects state an average certainty equivalent of $\$ 10$ for a 0.05 chance of $\$ 100$, and $\$ 63$ for a 0.9 chance of $\$ 100$. These findings motivate the overweighting of low tail probabilities and the underweighting of high tail probabilities, respectively.

Kahneman and Tversky emphasize that the transformed probabilities $\pi_{i}$ do not represent erroneous beliefs; rather, they are decision weights. In the framework of prospect theory, someone who is offered a 0.001 chance of winning $\$ 5,000$ knows exactly what it means for something to have a 0.001 probability of occurring; however, when evaluating the gamble, this person weights the $\$ 5,000$ by more than $0.001{ }^{4}$

Subsequent to Tversky and Kahneman’s (1992) paper on cumulative prospect theory, several studies have used more sophisticated techniques, in conjunction with new experimental data, to estimate the value function $v(\cdot)$ and the weighting function $w(\cdot)$ more accurately (Gonzalez and Wu 1999; Abdellaoui 2000; Bruhin, Fehr-Duda, and Epper 2010). These studies confirm the properties of these functions identified by Kahneman and Tversky: the loss aversion and diminishing sensitivity features of the value function, and the inverse S-shape of the weighting function. They provide especially strong support for probability weighting.

\section{Challenges in Applying Prospect Theory}

I noted earlier that the reason that developing applications of prospect theory in economics is taking a long time is because it is not always obvious how, exactly, to apply it. The central idea in prospect theory is that people derive utility from "gains" and "losses" measured relative to a reference point. But, in any given context, it is often

\footnotetext{
${ }^{4}$ For more information about the mechanics of probability weighting, see Tversky and Kahneman (1992), Wakker (2010), or Barberis (2012). It is interesting to think about the psychological foundations of probability weighting. Tversky and Kahneman (1992) and Gonzalez and Wu (1999) offer an interpretation based on the principle of diminishing sensitivity, while Rottenstreich and Hsee (2001) give an affect-based interpretation. More recently, Bordalo, Gennaioli, and Shleifer (2012) argue that salience is an important driver of probability weighting.
} 
unclear how to define precisely what a gain or loss is, not least because Kahneman and Tversky offered relatively little guidance on how the reference point is determined.

An example from finance may help to make this difficulty more concrete. Suppose that we want to predict what kind of portfolio an investor with prospect theory preferences will hold. Right away, we need to specify the "gains" and "losses" the investor is thinking about. Are they gains and losses in overall wealth, in the value of total stock market holdings, or in the value of specific stocks? If the investor's focus is on gains and losses in the value of his stock market holdings, does a "gain” in the stock market simply mean that the return on the stock market was positive? Or does it mean that the stock market return exceeded the risk-free rate, or the return the investor expected to earn? And is the investor thinking about annual gains and losses, or about monthly or even weekly fluctuations?

Some researchers have been scared off by the lack of a clear answer to these questions. Other researchers, however, have grasped the challenge of trying to understand how people conceptualize gains and losses in different contexts. The best way to tackle this question -- and the main approach researchers are taking -- is to derive the predictions of prospect theory under a variety of plausible definitions of gains and losses, and to then test these predictions, both in the laboratory and in the field. Through this process, we are gradually developing better theories of how people construe these gains and losses.

One significant attempt to clarify how people think about gains and losses is the work of Koszegi and Rabin (2006, 2007, 2009). In these papers, the authors propose a framework for applying prospect theory in economics that they argue is both disciplined and portable across different contexts. Their framework has several elements, but the most important is the idea that the reference point people use to compute gains and losses is their expectations, or "beliefs... held in the recent past about outcomes.” In particular, they propose that people derive utility from the difference between consumption and expected consumption, where the utility function exhibits loss aversion and diminishing sensitivity. To close the model, they also assume, as a first pass, that expectations are rational, in that they match the distribution of outcomes that people will face if they 
follow the plan of action that is optimal, given their expectations. This framework underlies a number of the applications I describe in the next section, especially those outside the area of finance, where a reference point such as the risk-free rate may be at least as plausible as one based on expectations.

Koszegi and Rabin (2006) also emphasize, as do other authors, that the question at hand is not whether we should replace traditional models with models in which people derive utility only from gains and losses, but rather whether it is useful to consider models in which people derive utility from both gains and losses and, as in traditional analysis, from consumption levels. After all, even if gains and losses matter, consumption levels surely matter too, and it would be a mistake to ignore them. In some models based on prospect theory, people do derive utility only from gains and losses. However, this modeling choice simply reflects a desire for tractability, not a belief that consumption levels do not matter.

While it is widely agreed that prospect theory offers an accurate description of risk attitudes in experimental settings, some have questioned whether its predictions will retain their accuracy outside the laboratory, where the stakes are often higher and where people may have significant experience making the decision at hand. Some direct evidence bears on this issue. For example, studies using data from game shows offering large prizes and from experiments conducted in poor countries where a U.S. researcher's budget represents a large amount of money have found that prospect theory continues to provide a good description of behavior under strong financial incentives (Kachelmeier and Shehata 1992; Post et al. 2008). And while List (2003, 2004) presents evidence that prospect theory is less accurate in describing the actions of experienced traders - I return to this evidence below - Pope and Schweitzer (2011) show that prospect theory plays a role even in the behavior of highly experienced and well-incentivized professionals: in particular, professional golfers exert significantly more effort when attempting a putt for par than when attempting a putt for scores other than par, a finding that is consistent with loss aversion relative to the reference point of par. 
In the end, the best way to find out whether prospect theory can shed light on behavior in real-world settings is to derive its predictions in these settings and to confront these predictions with data. I now discuss research of this type.

\section{Applications}

Prospect theory is, first and foremost, a model of decision-making under risk. As such, the most obvious places to look for applications are areas such as finance and insurance where attitudes to risk play a central role. I therefore start by discussing efforts to integrate prospect theory into these two fields and then turn to other areas of economics. $^{5}$

\section{Finance}

Finance is the field of economics where prospect theory has been most actively applied. The research in this area applies prospect theory in three main contexts: 1) the cross-section of average returns, where the goal is to understand why some financial assets have higher average returns than others; 2) the aggregate stock market; and 3) the trading of financial assets over time. I take each of these in turn.

Why do some securities have higher average returns than others? The best-known framework for thinking about this question is the famous Capital Asset Pricing Model, or CAPM. This model, which is typically derived by assuming, among other things, that investors evaluate risk according to expected utility, says that securities with higher "betas" - securities whose returns covary more with the return on the overall market should have higher average returns. Unfortunately, this prediction has not received much empirical support (in this journal, Fama and French 2004). This raises the question: Can we do a better job explaining the cross-section of average returns using a model in which

\footnotetext{
${ }^{5}$ See Camerer (2000), DellaVigna (2009), and Part IV of Kahneman (2011) for very useful earlier discussions of prospect theory applications in economics.
} 
investors evaluate risk in a psychologically more realistic way - specifically, according to prospect theory?

Barberis and Huang (2008) study asset prices in a one-period economy populated by investors who derive prospect theory utility from the change in the value of their portfolios over the course of the period. In this model, prospect theory leads to a new prediction, a prediction that does not emerge from the traditional analysis based on expected utility: namely, that a security's skewness in the distribution of its returns - even idiosyncratic skewness that is unrelated to the return on the overall market - will be priced. In particular, a positively skewed security - informally, a security whose return distribution has a right tail that is longer than its left tail -- will be overpriced, relative to the price it would command in an economy with expected utility investors, and will earn a lower average return.

The intuition for this result is straightforward. By taking a significant position in a positively skewed stock, say, investors give themselves the chance - a small chance, admittedly - of becoming wealthy, should the stock post an extraordinary right-tail performance, in other words, should it turn out to be "the next Google." Recall that, under probability weighting, investors overweight the tails of the distribution they are considering - here, the distribution of potential gains and losses in wealth. This means that they overweight the unlikely state of the world in which they make a lot of money by investing in the positively skewed stock. As a result, they are willing to pay a high price for the stock, even when it means earning a low average return on it. ${ }^{6}$

Over the past five years, prospect theory's implications for the cross-section of average returns have received significant empirical support. First, several papers, using a variety of techniques to measure skewness, have confirmed the basic prediction that more

\footnotetext{
${ }^{6}$ One attractive feature of this prediction, especially in light of the earlier discussion, is that it appears to be robust to different ways of defining what a "gain" or "loss" means to investors. In Barberis and Huang's (2008) model, investors derive prospect theory utility from changes in total wealth. The prediction that skewness will be priced continues to hold, however, if investors instead derive prospect theory utility from changes in the value of specific stocks that they own; indeed, in this case, the prediction follows even more directly. The prediction is also likely to survive the presence of expected utility investors in the economy. These investors may try to correct the overpricing of skewed securities by selling them short, but, due to the risks and costs of this strategy, their efforts are unlikely to be successful.
} 
positively skewed stocks will have lower average returns (Boyer, Mitton, and Vorkink 2010; Bali, Cakici, and Whitelaw 2011; Conrad, Dittmar, and Ghysels forthcoming).

Second, several papers have argued that the skewness prediction from prospect theory can shed light on other empirical patterns. For example, a well-known puzzle is that the long-term average return of stocks that conduct an initial public offering is below that of a control group of stocks - stocks of firms that are similar to the issuing firms on important dimensions, but that happened not to do an offering. One interesting property of returns on initial public offering stocks, however, is that they are highly positively skewed: most of these stocks don't perform particularly well, but some, like Google, or Microsoft, do incredibly well. As such, prospect theory says that stocks that do an offering should have lower average returns. Consistent with this hypothesis, Green and Hwang (2012) find that, the higher the predicted skewness of an initial public offering stock, the lower is its long-term average return.

Researchers have used the pricing of skewness predicted by prospect theory to address several other financial phenomena: the low average return of distressed stocks, of bankrupt stocks, of stocks traded over-the-counter, and of out-of-the-money options (all of these assets have positively skewed returns); the low relative valuations of conglomerates as compared to single-segment firms (single-segment firms have more skewed returns); and the lack of diversification in many household portfolios (households may choose to be undiversified in positively skewed stocks so as to give themselves at least a small chance of becoming wealthy). As such, prospect theory offers a unifying way of thinking about a number of seemingly unrelated facts. ${ }^{7}$

The aggregate stock market is the context for the best-known application of prospect theory in finance, namely Benartzi and Thaler's (1995) idea that prospect theory - and loss aversion in particular - can explain the famous equity premium puzzle, the fact that the average return of the U.S. stock market has historically exceeded the average return of Treasury bills by a much greater margin than predicted by traditional consumption-based models of asset prices. According to Benartzi and Thaler, an

\footnotetext{
${ }^{7}$ More discussion of these applications can be found in Mitton and Vorkink (2007), Eraker and Ready (2011), and Boyer and Vorkink (2012).
} 
individual who is thinking about investing in the stock market considers the historical distribution of annual stock market returns - annual because the performance of asset classes is often reported in annual terms. Since the investor is loss averse, the high dispersion of this distribution is very unappealing. To compensate for this, and thus to ensure that the investor is willing to hold his share of the supply of equity, the stock market needs to have a high average return, one that is significantly higher than on a safe asset like Treasury bills. ${ }^{8}$

Benartzi and Thaler's (1995) explanation relies not only on prospect theory, but also on an assumption known as "narrow framing," which occurs when an individual evaluates a risk separately from other concurrent risks. This manifests itself in Benartzi and Thaler's argument in the way investors apply prospect theory to changes in the value of one specific component of their wealth—namely, their stock market holdings. Narrow framing has been linked to many empirical findings - for example, Barberis, Huang, and Thaler (2006) argue that the widespread aversion to a 50:50 bet to win $\$ 110$ or lose $\$ 100$ is evidence not only of loss aversion but of narrow framing as well - and is frequently invoked in applications of prospect theory. However, we do not, as yet, have a full understanding of when and why it occurs. ${ }^{9}$

While Benartzi and Thaler's (1995) hypothesis is viewed by many as a plausible explanation of the equity premium puzzle, there are few direct empirical tests of it. The work that has followed their paper has instead focused on formalizing the original argument (for example, Barberis, Huang, and Santos 2001; Andries 2012; Pagel 2012). There is, however, some evidence for the related idea that loss aversion and narrow

\footnotetext{
${ }^{8}$ While Benartzi and Thaler (1995) focus on loss aversion, probability weighting also contributes to the high equity premium predicted by prospect theory. The reason is that the aggregate stock market is negatively skewed: it is subject to occasional large crashes. If investors overweight these rare events, they will require an even higher equity premium than that predicted by loss aversion alone (De Giorgi and Legg 2012). Probability weighting can therefore generate both the high average return on the overall stock market and the low average return on, for example, initial public offering stocks. In each case, the skewness of the asset, positive or negative, plays a key role.

${ }^{9}$ Why do we need narrow framing, rather than just loss aversion, to understand why people reject a 50:50 bet to win $\$ 110$ or lose $\$ 100$ ? Consider an individual who is loss averse, but who does not engage in narrow framing. When offered the 50:50 bet, this individual does not evaluate it in isolation, but in combination with other concurrent risks - financial risk, say, or labor income risk. Loosely speaking, these other risks diversify the risk of the 50:50 bet, making it more appealing. Indeed, Barberis, Huang, and Thaler (2006) show that, unless risk aversion is implausibly high, the individual will accept the bet. This suggests that, when people turn the bet down, as they typically do, narrow framing is at work: they reject the bet because they are loss averse and because they evaluate it in isolation.
} 
framing can explain the non-participation puzzle: the fact that, historically, most households did not participate in the stock market. Dimmock and Kouwenberg (2010), for example, find that survey-based measures of loss aversion predict stock market participation in a cross-section of households.

The third main strand of prospect theory research in finance is aimed at understanding how people trade financial assets over time. One target of interest is the “disposition effect," the empirical finding that both individual investors and mutual fund managers have a greater propensity to sell stocks that have risen in value since purchase, rather than stocks that have fallen in value (Odean 1998; Frazzini 2006). This behavior is puzzling because, over the horizon that these investors trade, stock returns exhibit "momentum": stocks that have recently done well continue to outperform, on average, while those that have done poorly continue to lag. As such, investors should concentrate their selling among stocks with poor past performance-but they do the opposite. This apparent unwillingness to sell stocks at a loss relative to purchase price has an important counterpart in the real estate market. Using data on Boston condominium prices from the 1990s, Genesove and Mayer (2001) find that if we take two condos, A and B, such that the two condos have the same expected selling price, but where $\mathrm{A}$ is expected to sell for less than its original purchase price while $\mathrm{B}$ is not, then the ask price that the seller posts for condo A is significantly higher than that for condo B, on average.

A long-standing idea is that this reluctance to sell assets at a loss follows naturally from prospect theory - in particular, from the convexity of the value function $v(\cdot)$ in the region of losses (Shefrin and Statman 1985). The intuition is that, if a stock (or a piece of real estate) performs poorly, this brings its owner into the loss region of the value function, where, because of the convexity, the owner becomes risk-seeking. As a result, this investor holds on to the stock (or the real estate) in the hope of breaking even later on.

A number of recent papers have tried to formalize this intuition, but that task turns out to be harder than expected. In particular, some researchers have argued that, for the argument to work, the value function needs to be much more convex over losses than the 
experimental evidence suggests that it actually is. This issue continues to be debated (Barberis and Xiong 2009; Meng 2012).

Meanwhile, some authors have argued that the disposition effect in both the stock market and the real estate market can be better understood as a consequence of "realization utility," the idea that people derive utility directly from selling an asset at a gain relative to purchase price -- and disutility from selling at a loss -- perhaps because they think that selling assets at a gain relative to purchase price is a good recipe for longterm wealth accumulation (or conversely, that selling assets at a loss relative to purchase price is a poor recipe for wealth accumulation). Barberis and Xiong (2012) show that, if the time discount rate is sufficiently positive, even linear realization utility can generate a strong disposition effect, as well as other empirically-observed trading patterns. While this explanation for the disposition effect differs from that based on the convexity of the prospect theory value function, it is ultimately still rooted in prospect theory, in that it relies on the investor deriving utility from gains and losses rather than from absolute wealth levels.

\section{Insurance}

Insurance is another area of economics where attitudes to risk play a central role. As such, it, too, is a promising place to look for applications of prospect theory. The most important consumer insurance markets are those for property and casualty insurance, mortality insurance -- the main products here are life insurance and annuities -- and health insurance. Thus far, prospect theory has been used to shed light on the first two of these three markets.

Sydnor (2010) studies the insurance decisions of 50,000 customers of a large home insurance company. The main decision that these households have to make is to choose a deductible from a menu of four possibilities: $\$ 100, \$ 250, \$ 500$, and $\$ 1,000$. Sydnor finds that the households that choose a \$500 deductible pay an average premium of $\$ 715$ per year. In choosing this policy, these households all turned down a policy with a $\$ 1,000$ deductible whose average premium was just $\$ 615$ per year. Given that the annual claim rate is approximately 5 percent, these households agreed to pay $\$ 100$ a year 
to insure against a 5 percent chance of paying an additional \$500 in the event of a claim! In an expected utility framework, this choice can only be rationalized by unreasonably high levels of risk aversion.

What explains this behavior? Sydnor (2010) ultimately favors an approach based on the probability weighting component of prospect theory. Under probability weighting, a household overweights tail events - in this context, the state of the world in which a claim occurs and it has to pay the deductible. Due to its extra focus on this unlikely but unpleasant outcome, the household is willing to pay a higher premium for a policy with a lower deductible. Sydnor also notes that the extent to which prospect theory can explain the data depends on the household's reference point. If the reference point is simply the household's wealth at the time it is choosing an insurance policy, then prospect theory can go some of the way, but not all the way, toward explaining the high premium the household chooses to pay. However, if, as Koszegi and Rabin (2007) propose, the reference point is expectations about future outcomes, then prospect theory may be able to explain fully the choices we observe. The intuition is that, since a premium is a payment that a household expects to make, while a deductible is a payment that arises only in the unlikely event of a claim, the household doesn't experience as much loss aversion when it pays the premium as it does when it pays the deductible. As a result, it is willing to pay a higher premium.

Barseghyan et al. (2012) pursue this line of research further. They analyze a formal structural model of insurance choice for a prospect theory household whose reference point is its expectations about future outcomes, and estimate the model using data on home and automobile insurance choices. They, too, find evidence that probability weighting plays a role in household decisions. More precisely, their estimates suggest that, when a household chooses a policy, it significantly overweights the state of the world in which it has to file a claim. As with Sydnor's analysis, this could be because it overestimates the probability of having to file a claim; or because, as in probability weighting, it applies inflated decision weights to tail outcomes.

There are several puzzles relating to the market for mortality insurance, but the best known is the annuitization puzzle: the fact that, at the point of retirement, people 
allocate a much smaller fraction of their wealth to annuity products than normative models suggest they should (in this journal, Benartzi, Previtero, and Thaler 2011).

Hu and Scott (2007) argue that prospect theory offers a way of understanding why annuities are unpopular. In their framework, people think of an annuity as a risky gamble whose payoff - unknown at the moment of retirement - is the present value of the payouts to be received from the annuity before death, minus the amount initially paid for the annuity. So, if someone purchases an annuity at age 65 and dies at age 66, this represents a large "loss": the individual paid a lot for the annuity but received very little in return. Conversely, if this person lives until the age of 90, this represents a large "gain," in the sense that much more was received from the annuity than was initially paid in. Hu and Scott show that, if the annuity is viewed as a gamble in this way, and if it is evaluated according to prospect theory, then it will be unattractive. Loss aversion plays the largest role here: simply put, the annuity is unappealing because the individual is more sensitive to the potential loss on the annuity (if he dies soon) than to the potential gain (if he lives a long time). But probability weighting also matters: while the chance of dying very soon and hence receiving a large loss on the annuity is low, probability weighting means that this unlikely event looms large in the decision-maker's thinking. ${ }^{10}$

\section{The Endowment Effect}

Prospect theory was originally developed as a theory of risky choice. However, in an influential paper, Thaler (1980) argues that several of the ideas in the theory may also be useful for thinking about riskless choice. The natural framework, formalized by Tversky and Kahneman (1991) and Koszegi and Rabin (2006), is one where the individual derives utility from consumption relative to some reference level of consumption; and where the utility function exhibits loss aversion and diminishing sensitivity, so that, for example, the individual is more sensitive to declines in consumption relative to the reference point than to increases. A large literature, starting with Thaler (1980), has argued that some experimental findings that come under the label

\footnotetext{
${ }^{10}$ See Gottlieb (2012) for more discussion of this and other applications of prospect theory in the market for mortality insurance.
} 
“endowment effect” offer strong support for this prospect theory model of riskless choice.

The term "endowment effect" actually refers to two distinct findings that may, or may not, be related. The first is sometimes known as "exchange asymmetries," and the second, as "WTA/WTP gaps," the gaps between willingness to accept and willingness to pay. ${ }^{11}$

The classic reference on exchange asymmetries is Knetsch (1989). He gives half the participants in his experiment a mug, and the other half, a candy bar. After a few minutes, during which the participants are asked to complete an unrelated questionnaire, Knetsch asks those who initially received the mug whether they would like to exchange it for the candy, and those who initially received the candy, whether they would like to exchange it for the mug. If, as in traditional economic analysis, preferences over goods do not depend on initial endowments, then whether a participant chooses to go home with a mug or with candy should not depend on the good that this participant was initially given. In fact, Knetsch finds that the initial allocation has a huge effect on subsequent choice: 89 percent of those initially given a mug opt to keep it, while only 10 percent of those initially given candy opt to exchange it for a mug.

The standard reference for willingness to accept/willingness to pay gaps is Kahneman, Knetsch, and Thaler (1990), and specifically, their Experiment 5. In this experiment, half the participants are given a mug and are asked to state, for a given list of prices, whether, for each price, they would give up the mug in exchange for that amount of money; in other words, they are asked their willingness to accept. The remaining participants are asked to state, for a given list of prices, whether, for each price, they would be willing to pay that amount of money to obtain the mug; in other words, they are asked their willingness to pay. According to traditional analysis, there should be almost no difference between these two measures. Kahneman et al. (1990) find large differences, however: the median willingness to pay is $\$ 2.25$ but the median willingness to accept is $\$ 5.75$.

\footnotetext{
${ }^{11}$ The term "endowment effect" can be confusing not just because it refers to two separate empirical findings, but also because it is sometimes used to refer to evidence, and sometimes to a theory of that evidence, one based on prospect theory. Here, I use it to refer only to evidence.
} 
A leading hypothesis is that these two findings reflect the same underlying psychology of loss aversion. In the exchange asymmetry experiment, participants view an exchange as "losing" the item they were initially given and "gaining" the other item. Since they are more sensitive to losses than to gains, an exchange is unattractive, which explains why most of them stick with their initial endowment. Similarly, in the willingness to accept/willingness to pay experiment, loss aversion predicts that people will demand much more money in order to give up a mug they have previously received - here, giving up the mug is a "loss" - than they will be willing to pay in order to get one; getting a mug is the corresponding "gain.",

List (2003, 2004) questions the robustness of exchange asymmetries. He conducts Knetsch-type experiments at a sports card market. His participants include both nondealers and dealers; in other words, people who do not trade sports memorabilia very often, and people who do. He finds strong evidence of exchange asymmetries in the first group, but not in the second: dealers are much more willing to exchange an initial object they are given for another one of similar value. List uses this evidence to suggest that prospect theory may be less useful in describing the behavior of experienced economic actors.

However, Koszegi and Rabin (2006) argue that List's results may be fully consistent with prospect theory, albeit with an implementation of prospect theory that takes the reference point to be a person's expectations about future outcomes. Intuitively, there are fewer exchange asymmetries among dealers because dealers expect to exchange objects that come into their possession, and, as a result, do not experience much loss aversion when they give the objects up. This hypothesis is now being formally tested (Ericson and Fuster 2011; Heffetz and List 2012).

Plott and Zeiler $(2005,2007)$ show that changes in experimental conditions can significantly affect the magnitude of exchange asymmetries and willingness to accept/willingness to pay gaps, leading them to question the loss aversion interpretation

\footnotetext{
${ }^{12}$ Samuelson and Zeckhauser (1988) apply this logic more broadly. They argue that, since departing from the status quo usually entails gaining something but also losing something, and since, under loss aversion, losses loom larger than gains, people will exhibit a "status quo bias": they will cling too tightly to the status quo. They present both experimental and field evidence consistent with such a bias.
} 
of these effects. For example, they suggest that the exchange asymmetries documented by Knetsch (1989) may be due to subjects' (incorrectly) perceiving the object they were initially given as more valuable; or to them thinking of the initial object as a gift, one that it would be impolite to exchange. Plott and Zeiler's results have attracted a lot of attention, but remain controversial. For example, Koszegi and Rabin (2006) argue, once again, that the results are consistent with loss aversion when the reference point is the decision maker's expectations. As I noted above, this hypothesis is currently being tested.

\section{Consumption-Savings Decisions}

Koszegi and Rabin (2009) propose a way of incorporating the ideas in prospect theory into a dynamic model of consumption choice. The model builds on the authors' earlier idea that expectations are an important reference point. At each time $t$, the individual derives utility from two sources: from the difference between actual consumption at time $t$ and what that person recently expected consumption at that time to be; but also from the difference between the individual's currently projected consumption at each future date and the consumption that person recently expected at that date. These utility terms incorporate loss aversion: the individual is more sensitive to news that consumption at some point will be lower than expected than to news that it will be higher than expected. The authors also assume that the individual is more sensitive to news that current consumption is different from its recently expected level than to news that future consumption will differ from its recently expected level.

This framework has some interesting implications. First, it suggests a new motive for precautionary saving: an individual facing income uncertainty will save more today so as to reduce the expected pain from finding out, later on, that it has become necessary to consume less than previously planned. Second, an individual has a tendency to overconsume, but for a reason that is quite different from the one noted in the literature on hyperbolic discounting. Specifically, in each period, the person has an incentive to surprise himself with a little extra consumption. While this comes at the cost of lower consumption later, the fact that the individual is less sensitive to news about future consumption than to news about current consumption makes the tradeoff worthwhile. 
Pagel (2012) builds on these insights to show, in a more comprehensive analysis, that the Koszegi and Rabin (2009) framework can explain a number of facts about household consumption. For example, she finds that the precautionary saving and overconsumption motives I just described combine to produce a realistic hump-shaped pattern of consumption over the life cycle. She also finds that the framework can shed light on the “excess sensitivity” and “excess smoothness” puzzles, whereby consumption appears to adjust insufficiently to income shocks. The intuition is that, upon receiving a negative income shock, the individual prefers to lower future consumption rather than current consumption. After all, news that future consumption will be lower than expected is less painful than news that current consumption is lower than expected. Moreover, when, at some future time, the individual actually lowers consumption, the pain will be limited because, by that point, expectations will have adjusted downwards.

\section{Industrial Organization}

When consumers have prospect theory preferences, firms may adopt a corresponding strategy for price-setting. For example, Heidhues and Koszegi (2012) consider a risk-neutral monopolist selling to a consumer who is loss averse, both in the dimension of the good the consumer is thinking of buying and in the dimension of money. As suggested by Koszegi and Rabin (2006), the reference point is determined by expectations about future outcomes. In other words, the consumer derives utility from the amount of money spent relative to the amount of money he expected to spend; and the utility derived from obtaining the good depends on the probability with which the consumer expected to obtain it (the higher this probability, the lower the utility of obtaining the good).

It turns out that the optimal pricing strategy for this monopolist is one that supermarkets and other retailers often use in practice, namely to set a price that jumps back and forth every so often between a high "regular” price and a variety of lower sale prices. The full intuition for this conclusion has several components, but one key idea is that, by occasionally setting a low sale price at which the consumer is certain to want to buy, the firm ensures that the consumer will buy even at high prices that exceed his 
valuation of the good. The reason is that, because the consumer expects to obtain the good with some probability (specifically, if there is a sale on), loss aversion means that it will be painful to leave the store without the good, even if its price is high. Indeed, it turns out that, by alternating between high and low prices, the firm can induce the consumer to pay an average price that exceeds his valuation of the good.

\section{Labor Supply}

Prospect theory may be helpful for understanding some aspects of how labor supply reacts to wages. Research on this topic has centered on the labor supply of cab drivers. It may seem odd to focus on such a narrow segment of the labor market, but there is a reason. Models of labor supply typically assume that workers can choose the quantity of hours that they work. Driving a cab is one profession where this is literally true.

Using data on cab drivers in New York City, Camerer et al. (1997) find that the number of hours that a driver works on a given day is strongly inversely related to his average hourly wage on that day. Although they do not present a formal model, the authors suggest that the data are consistent with a framework in which the driver derives prospect theory utility from the difference between his daily income and some target level, or reference level, of income. In particular, due to loss aversion, earning \$20 less than the target is much more painful than earning \$20 more than the target is pleasurable. It is easy to see that a driver with these preferences will typically stop work for the day after reaching the target income level. Since the driver reaches this target more quickly on days when earnings are higher, he stops working sooner on these days. ${ }^{13}$

A key difficulty in providing further evidence for Camerer et al.'s hypothesis is that it is not clear what determines a driver's target income. Koszegi and Rabin (2006) break this impasse by proposing that the target is based on the driver's expectations.

\footnotetext{
${ }^{13}$ This study was received skeptically in some quarters: for example, Farber $(2005,2008)$. The skepticism arose, in part, because Camerer et al.’s (1997) results seemed to suggest, counterintuitively, that people work less when their expected wage is high. However, Koszegi and Rabin (2006) argue that this is not the right interpretation of the evidence. Cab drivers probably do work more on days when their expected earnings are higher. What Camerer et al. (1997) show is that they stop working when their earnings early in a shift have been unexpectedly high. There is no contradiction here. Intra-day wages are not significantly autocorrelated: unexpectedly high wages in the morning do not affect expected earnings in the afternoon.
} 
Specifically, they propose a model of labor supply in which the worker derives utility from the absolute levels of income and hours worked, as in traditional analysis; but in

which the worker also derives prospect theory utility, on a daily basis, from the difference between income and expected income, and from the difference between the number of hours worked and the expected number of hours worked.

Crawford and Meng (2011) analyze this model in detail. They point out that, to a first approximation, a driver with these preferences will stop working either when he hits the income target - loss aversion means that the marginal utility of an additional dollar is much lower once he reaches this target -- or when he hits the hours target (again, loss aversion means that it is much more painful to work an additional hour once this target is reached). The authors test this prediction, again using data on New York City cab drivers. As suggested by Koszegi and Rabin, they identify a driver's targets for income and hours on the job with expected income and hours on the job, and estimate these using the driver's history of income earned and hours worked on each day of the week. The data seem to support this model. In particular, drivers appear to stop when they reach the second of the two targets; note that this is the income target if the driver's earnings early in the shift are lower than expected, and the hours target otherwise. These results broadly confirm Camerer et al.'s (1997) initial hypothesis, but also show the importance of identifying a driver's target with his expectations and of allowing for loss aversion both in the dimension of income and in the dimension of hours worked: the data are not consistent with a model in which the driver is loss averse only in the dimension of income.

\section{Other Applications}

There are other promising applications of prospect theory that I will not discuss in detail. Some recent papers study contracting between a principal and an agent when the agent has prospect theory preferences. Insights from these papers can help explain the prevalence of stock options, rather than just stock, in the compensation packages of both executive and non-executive employees (Dittman, Maug, and Spalt 2010; Spalt forthcoming). 
Prospect theory has also been applied, with some success, to understanding betting markets. Snowberg and Wolfers (2010) show that probability weighting, in particular, offers a good way of thinking about one of the best-known betting anomalies, the "favorite-longshot bias," in which the market odds of longshots in horse races significantly overstate their chance of winning. Barberis (2012) uses probability weighting to explain a broader phenomenon, namely, the popularity of casino gambling. In a dynamic setting - a casino that offers gamblers a sequence of bets, say - probability weighting predicts a time inconsistency. Barberis (2012) analyzes this inconsistency and argues that, far from being an unattractive feature of prospect theory, it may actually be helpful for understanding observed behavior - for example, the way people often gamble longer in casinos than they were originally intending to, particularly when losing.

There are areas of economics where prospect theory has not been applied very extensively, even though it has the potential to offer useful insights. Public finance, health economics, and macroeconomics are three such fields. To give just one example among many, the concept of loss aversion relative to a reference point may be a helpful way of thinking about the downward rigidity of nominal wages that plays a significant role in some models of the business cycle.

All of the applications discussed above fall under the umbrella of positive economics: we used prospect theory to make sense of observed behavior. Some applications, however, use the insights of prospect theory in a more prescriptive way: to nudge people toward behaviors that are viewed as more desirable. For example, Fryer et al. (2012), Levitt et al. (2012), and Hossain and List (forthcoming) find that teachers, students, and factory workers, respectively, exert more effort when they are given monetary incentives framed as losses, rather than gains-a finding that is consistent with loss aversion. Loss aversion is also a major influence in the design of Thaler and Benartzi's (2004) Save More Tomorrow framework for increasing saving in retirement plans: in this framework, employees' saving rates are increased only when they receive pay raises, thereby protecting them from any painful "losses" in nominal take-home pay.

The common preference for lottery-like payoffs, a preference embedded in probability weighting, has also been used to encourage a range of behaviors. In many 
countries, banks offer savings' accounts that, in lieu of paying interest, enter depositors into a lottery. These products have proven popular, particularly among low-income individuals (Kearney et al. 2010); for legal reasons, however, they are not available in the United States. In a different setting, Volpp et al. (2008a, b) try to encourage people to lose weight, or to stick to a drug regimen, by entering them into a lottery if they lose a certain number of pounds or remember to take their pills on time. This turns out to be an effective intervention.

\section{Discussion}

One might have thought that, more than 30 years after the publication of Kahneman and Tversky's (1979) paper on prospect theory, we would have a clear sense of how important a role their theory can play in economic analysis. This is not the case. Because of the difficulties inherent in applying prospect theory in economics, it is only in the last few years that we have made real progress in doing so. Indeed, this research effort is still in its early stages. While it is too soon, then, to draw any firm conclusions about prospect theory's place in economics, a few observations seem appropriate.

At this point, the fields of economics where prospect theory has been most extensively applied are finance and insurance. This emphasis is not surprising. Prospect theory came into being as a model of decision-making under risk; it may therefore be best-suited to settings where attitudes to risk play a crucial role. Indeed, until a few years ago, the only significant applications of prospect theory outside finance and insurance were the endowment effect and the labor supply of cab drivers - a remarkably short list, and one that can be criticized: the endowment effect for being "only" an experimental finding, and the work on labor supply for being relevant to a potentially narrow segment of the working population. Nonetheless, a clear trend of the past few years is that prospect theory has extended its reach into several other areas of economics - to consumption choice, to industrial organization, to contract theory, to name just a few and has done so in promising ways. This trend is sure to continue. Ten years from now, 
prospect theory's visibility in these other areas may well match or exceed its visibility in finance.

The research described in this paper also gives us a preliminary sense of the relative importance of the various components of prospect theory in economic decisionmaking. Reference-dependence is the most basic idea in prospect theory, and if any element of the theory finds a permanent place in economic analysis, it will surely be this one. Loss aversion clearly also plays a useful role in many of the applications discussed above. Diminishing sensitivity, by contrast, seems much less important. It features in one of our applications - the disposition effect - but even there, its role is unclear. Probability weighting, on the other hand, has drawn increasing interest in recent years. Indeed, within the risk-related areas of finance, insurance, and gambling, probability weighting plays a more central role than loss aversion, and has attracted significantly more empirical support.

The fundamental difficulty in applying prospect theory in economics is that, even if we accept that the carriers of utility are gains and losses, it is often unclear what a gain or loss represents in any given situation. This difficulty remains unresolved; addressing it is a key challenge. Koszegi and Rabin (2006) provide a very thoughtful analysis of this issue, but their proposal remains a hypothesis in need of more testing and, in any case, is unlikely to be completely correct. This may be particularly true in the field of finance where there are natural reference points other than expectations, and where the gains and losses that investors think about are often more likely to be the monetary gains and losses on specific investments ("narrow framing") rather than the gains and losses in consumption that Koszegi and Rabin (2006) stress.

In this essay, I have argued that a variety of observed behaviors stem from thinking about risk in the way described by prospect theory. If subsequent research confirms this claim, the natural next question is: Should anything be done about it? If people avoid annuities, “overpay” for initial public offerings, or go to casinos because they evaluate risk according to prospect theory, does that mean that these behaviors are mistakes?; and, if so, should there be an effort to change people's behavior? These are difficult questions to answer because we do not, as yet, have a full understanding of 
whether loss aversion or probability weighting should be thought of as mistakes. One possible approach to studying this issue is to explain to people, in an appropriate way, that they may be acting the way they are because of prospect theory preferences; and to then see if, armed with this information, they change their behavior. ${ }^{14}$

Even prospect theory’s most ardent fan would concede that economic analysis based on this theory is unlikely to replace the analysis that we currently present in our introductory textbooks. It makes sense to teach students the fundamental concepts of economics using a traditional utility function, not least because this is simpler than using prospect theory. Indeed, while Mankiw’s best-selling undergraduate economics textbook devotes part of a chapter to behavioral economics, it makes no specific mention of prospect theory anywhere in its 900 pages. However, as prospect theory becomes more established in economics, a reasonable vision for future textbooks is that, once they complete the traditional coverage of some topic - of consumer behavior, say, or of consumption-savings decisions, industrial organization, or labor supply - they will follow this with a section or chapter that asks: Can we make more sense of the data using models that are based on psychologically more realistic assumptions? I expect prospect theory to figure prominently in some of these, as yet unwritten, chapters.

\footnotetext{
${ }^{14}$ A behavior that is closely associated with prospect theory and that is widely viewed as a mistake is narrow framing: evaluating a risk in isolation rather than in combination with other concurrent risks. If some phenomenon - non-participation in the stock market, say - is traced to narrow framing, it is easier to make a case for trying to change the pattern of thinking that underlies the phenomenon.
} 


\section{References}

Abdellaoui, Mohammed. 2000. "Parameter-free Elicitation of Utility and Probability Weighting Functions.” Management Science 46(11): 1497-1512.

Andries, Marianne. 2012. "Consumption-based Asset Pricing with Loss Aversion.” Unpublished paper.

Bali, Turan, Nusret Cakici, and Robert Whitelaw. 2011. "Maxing Out: Stocks as Lotteries and the Cross-section of Expected Returns.” Journal of Financial Economics 99(2): 427-446.

Barberis, Nicholas. 2012. “A Model of Casino Gambling.” Management Science 58(1): $35-51$.

Barberis, Nicholas, and Ming Huang. 2008. "Stocks as Lotteries: The Implications of Probability Weighting for Security Prices.” American Economic Review 98(5): 20662100.

Barberis, Nicholas, Ming Huang, and Tano Santos. 2001. "Prospect Theory and Asset Prices.” Quarterly Journal of Economics 116(1): 1-53.

Barberis, Nicholas, Ming Huang, and Richard Thaler. 2006. "Individual Preferences, Monetary Gambles, and Stock Market Participation: A Case for Narrow Framing.” American Economic Review 96(4): 1069-1090.

Barberis, Nicholas, and Wei Xiong. 2009. "What Drives the Disposition Effect? An Analysis of a Long-standing Preference-based Explanation.” Journal of Finance 64(2): 751-784.

Barberis, Nicholas, and Wei Xiong. 2012. "Realization Utility.” Journal of Financial Economics 104(2): 251-271.

Barseghyan, Levon, Francesca Molinari, Ted O'Donoghue, and Joshua Teitelbaum. 2012. "The Nature of Risk Preferences: Evidence from Insurance Choices.” Unpublished paper.

Benartzi, Shlomo, Alessandro Previtero, and Richard H. Thaler. 2011.

“Annuitization Puzzles.” Journal of Economic Perspectives 25(4): 143-164.

Benartzi, Shlomo, and Richard Thaler. 1995. "Myopic Loss Aversion and the Equity Premium Puzzle.” Quarterly Journal of Economics 110(1): 73-92.

Bordalo, Pedro, Nicola Gennaioli, and Andrei Shleifer. 2012. "Salience Theory of Choice Under Risk.” Quarterly Journal of Economics 127(3): 1243-1285. 
Boyer, Brian, Todd Mitton, and Keith Vorkink. 2010. "Expected Idiosyncratic Skewness.” Review of Financial Studies 23(1): 169-202.

Boyer, Brian, and Keith Vorkink. 2012. “Stock Options as Lotteries.” Unpublished paper.

Bruhin, Adrian, Helga Fehr-Duda, and Thomas Epper. 2010. "Risk and Rationality: Uncovering Heterogeneity in Probability Distortion.” Econometrica 78(4): 1375-1412.

Camerer, Colin. 2000. "Prospect Theory in the Wild: Evidence from the Field.” In Choices, Values and Frames, edited by Daniel Kahneman and Amos Tversky. Cambridge University Press.

Camerer, Colin, Linda Babcock, George Loewenstein, and Richard Thaler. 1997. "Labor Supply of New York City Cabdrivers: One Day at a Time.” Quarterly Journal of Economics 112(2): 407-441.

Conrad, Jennifer, Robert Dittmar, and Eric Ghysels. Forthcoming. "Ex Ante Skewness and Expected Stock Returns.” Journal of Finance.

Crawford, Vincent, and Juanjuan Meng. 2011. “New York City Cab Drivers’ Labor Supply Revisited: Reference-Dependent Preferences with Rational Expectations Targets for Hours and Income.” American Economic Review 101(5): 1912-1932.

De Giorgi, Enrico, and Shane Legg. 2012. "Dynamic Portfolio Choice and Asset Pricing with Narrow Framing and Probability Weighting.” Journal of Economic Dynamics and Control 36(7): 951-972.

DellaVigna, Stefano. 2009. "Psychology and Economics: Evidence from the Field.” Journal of Economic Literature 47(2): 315-372.

Dimmock, Stephen, and Roy Kouwenberg. 2010. "Loss-aversion and Household Portfolio Choice.” Journal of Empirical Finance 17(3): 441-459.

Dittman, Ingolf, Ernst Maug, and Oliver Spalt. 2010. "Sticks or Carrots? Optimal CEO Compensation when Managers are Loss Averse.” Journal of Finance 65(6): 20152050.

Eraker, Bjorn, and Mark Ready. 2011. "Do Investors Overpay for Stocks with Lotterylike Payoffs? An Examination of the Returns on OTC Stocks.” Unpublished paper.

Ericson, Keith, and Andreas Fuster. 2011. "Expectations as Endowments: Evidence on Reference-Dependent Preferences from Exchange and Valuation Experiments.” Quarterly Journal of Economics 126(4): 1879-1907. 
Fama, Eugene, and Kenneth French. 2004. “The Capital Asset Pricing Model: Theory and Evidence.” Journal of Economic Perspectives 18(3): 25-46.

Farber, Henry. 2005. "Is Tomorrow Another Day? The Labor Supply of New York City Cabdrivers.” Journal of Political Economy 113(1): 46-82.

Farber, Henry. 2008. "Reference-Dependent Preferences and Labor Supply: The Case of New York City Taxi Drivers.” American Economic Review 98(3): 1069-1082.

Frazzini, Andrea. 2006. “The Disposition Effect and Underreaction to News.” Journal of Finance 61(4): 2017-2046.

Fryer, Roland, Steven Levitt, John List, and Sally Sadoff. 2012. “Enhancing the Efficacy of Teacher Incentives through Loss Aversion: A Field Experiment.” NBER Working paper 18237.

Genesove, David, and Christopher Mayer. 2001. "Loss Aversion and Seller Behavior: Evidence from the Housing Market.” Quarterly Journal of Economics 116(4): 12331260.

Gonzalez, Richard, and George Wu. 1999. "On the Shape of the Probability Weighting Function.” Cognitive Psychology 38(1): 129-166.

Gottlieb, Daniel. 2012. “Prospect Theory, Life Insurance, and Annuities.” Unpublished paper.

Green, Clifton, and Byoung Hwang. 2012. "Initial Public Offerings as Lotteries:

Skewness Preference and First-Day Returns.” Management Science 58(2): 432-444.

Heffetz, Ori, and John List. 2012. “Assignment, Expectations, and Endowment: Variations in the Lab and Their Effects on Choice.” Unpublished paper.

Heidhues, Paul, and Botond Koszegi. 2012. “Regular Prices and Sales.” Unpublished paper.

Hossain, Tanjim, and John List. Forthcoming. "The Behavioralist Visits the Factory: Increasing Productivity Using Simple Framing Manipulations.” Management Science.

Hu, Wei-Yin, and Jason Scott. 2007. "Behavioral Obstacles in the Annuity Market." Financial Analysts Journal 63(6): 71-82.

Kachelmeier, Steven, and Mohamed Shehata. 1992. "Examining Risk Preferences Under High Monetary Incentives: Experimental Evidence from the People's Republic of China.” American Economic Review 82(5): 1120-1141. 
Kahneman, Daniel. 2011. Thinking, Fast and Slow. New York: Farrar, Straus, and Giroux.

Kahneman, Daniel, Jack Knetsch, and Richard Thaler. 1990. "Experimental Tests of the Endowment Effect and the Coase Theorem.” Journal of Political Economy 98(6): 1325-1348.

Kahneman, Daniel, and Amos Tversky. 1979. "Prospect Theory: An Analysis of Decision Under Risk.” Econometrica 47(2): 263-291.

Kearney, Melissa, Peter Tufano, Jonathan Guryan, and Erik Hurst. 2010. "Making Savers Winners: An Overview of Prize-linked Savings Products.” NBER Working paper 16433.

Knetsch, Jack. 1989. “The Endowment Effect and Evidence of Nonreversible Indifference Curves.” American Economic Review 79(5): 1277-1284.

Koszegi, Botond, and Matthew Rabin. 2006. “A Model of Reference-Dependent Preferences.” Quarterly Journal of Economics 121(4): 1133-1165.

Koszegi, Botond, and Matthew Rabin. 2007. "Reference-Dependent Risk Attitudes." American Economic Review 97(4): 1047-1073.

Koszegi, Botond, and Matthew Rabin. 2009. "Reference-Dependent Consumption Plans.” American Economic Review 99(3): 909-936.

Levitt, Steven, John List, Susanne Neckerman, and Sally Sadoff. 2012. "The Behavioralist Goes to School: Leveraging Behavioral Economics to Improve Educational Performance.” NBER Working paper 18165.

List, John. 2003. “Does Market Experience Eliminate Market Anomalies?” Quarterly Journal of Economics 118(1): 41-71.

List, John. 2004. "Neoclassical Theory Versus Prospect Theory: Evidence from the Marketplace.” Econometrica 72(2): 615-625.

Meng, Juanjuan. 2012. “Can Prospect Theory Explain the Disposition Effect? A New Perspective on Reference Points.” Unpublished paper.

Mitton, Todd, and Keith Vorkink. 2007. "Equilibrium Underdiversification and the Preference for Skewness.” Review of Financial Studies 20(4): 1255-1288.

Odean, Terrance. 1998. “Are Investors Reluctant to Realize Their Losses?” Journal of Finance 53(5): 1775-1798. 
Pagel, Michaela. 2012. "Expectations-based Reference-Dependence and Asset Pricing.” Unpublished paper.

Pagel, Michaela. 2012. “Expectations-based Reference-Dependent Life-cycle Consumption.” Unpublished paper.

Plott, Charles, and Kathryn Zeiler. 2005. “The Willingness to Pay-Willingness to Accept Gap, the "Endowment Effect," Subject Misconceptions, and Experimental Procedures for Eliciting Valuations.” American Economic Review 95(3): 530-545.

Plott, Charles, and Kathryn Zeiler. 2007. "Exchange Asymmetries Incorrectly Interpreted as Evidence of Endowment Effect Theory and Prospect Theory?” American Economic Review 97(4): 1449-1466.

Pope, Devin, and Maurice Schweitzer. 2011. "Is Tiger Woods Loss Averse? Persistent Bias in the Face of Experience, Competition, and High Stakes." American Economic Review 101(1): 129-157.

Post, Thierry, Martin van den Assem, Guido Baltussen, and Richard Thaler. 2008. "Deal or No Deal? Decision-making Under Risk in a Large-Payoff Game Show." American Economic Review 98(1): 38-71.

Rabin, Matthew. 2000. "Risk Aversion and Expected-Utility Theory: A Calibration Theorem.” Econometrica 68(5): 1281-1292.

Rottenstreich, Yuval, and Christopher Hsee. 2001. "Money, Kisses, and Electric Shocks: on the Affective Psychology of Risk.” Psychological Science 12(3): 185-190.

Samuelson, William, and Richard Zeckhauser. 1988. "Status Quo Bias in Decisionmaking.” Journal of Risk and Uncertainty 1(1): 7-59.

Shefrin, Hersh, and Meir Statman. 1985. "The Disposition to Sell Winners Too Early and Ride Losers Too Long: Theory and Evidence.” Journal of Finance 40(3): 777-790.

Snowberg, Erik, and Justin Wolfers. 2010. "Explaining the Favorite-Long Shot Bias: Is it Risk-Love or Misperceptions?” Journal of Political Economy 118(4): 723-746.

Spalt, Oliver. Forthcoming. "Probability Weighting and Employee Stock Options.” Journal of Financial and Quantitative Analysis.

Sydnor, Justin. 2010. “(Over)insuring Modest Risks.” American Economic Journal: Applied Economics 2(4): 177-199.

Thaler, Richard. 1980. “Toward a Positive Theory of Consumer Choice.” Journal of Economic Behavior and Organization 1(1): 39-60. 
Thaler, Richard, and Shlomo Benartzi. 2004. "Save More Tomorrow: Using Behavioral Economics to Increase Employee Saving.” Journal of Political Economy 112(S1): S164-S187.

Tversky, Amos, and Daniel Kahneman. 1991. "Loss Aversion in Riskless Choice: A Reference-Dependent Model.” Quarterly Journal of Economics 106(4): 1039-1061.

Tversky, Amos, and Daniel Kahneman. 1992. "Advances in Prospect Theory:

Cumulative Representation of Uncertainty.” Journal of Risk and Uncertainty 5(4): $297-$ 323.

Volpp, Kevin, Leslie John, Andrea Troxel, Laurie Norton, Jennifer Fassbender, and George Loewenstein. 2008a. "Financial Incentive-based Approaches for Weight Loss.” Journal of the American Medical Association 300(22): 2631-2637.

Volpp, Kevin, George Loewenstein, Andrea Troxel, Jalpa Dosli, Maureen Price, Mitchell Laskin, and Stephen Kimmel. 2008b. "A Test of Financial Incentives to Improve Warfarin Adherence.” BMC Health Services Research 8: 272.

Wakker, Peter. 2010. Prospect Theory: For Risk and Ambiguity. Cambridge University Press. 


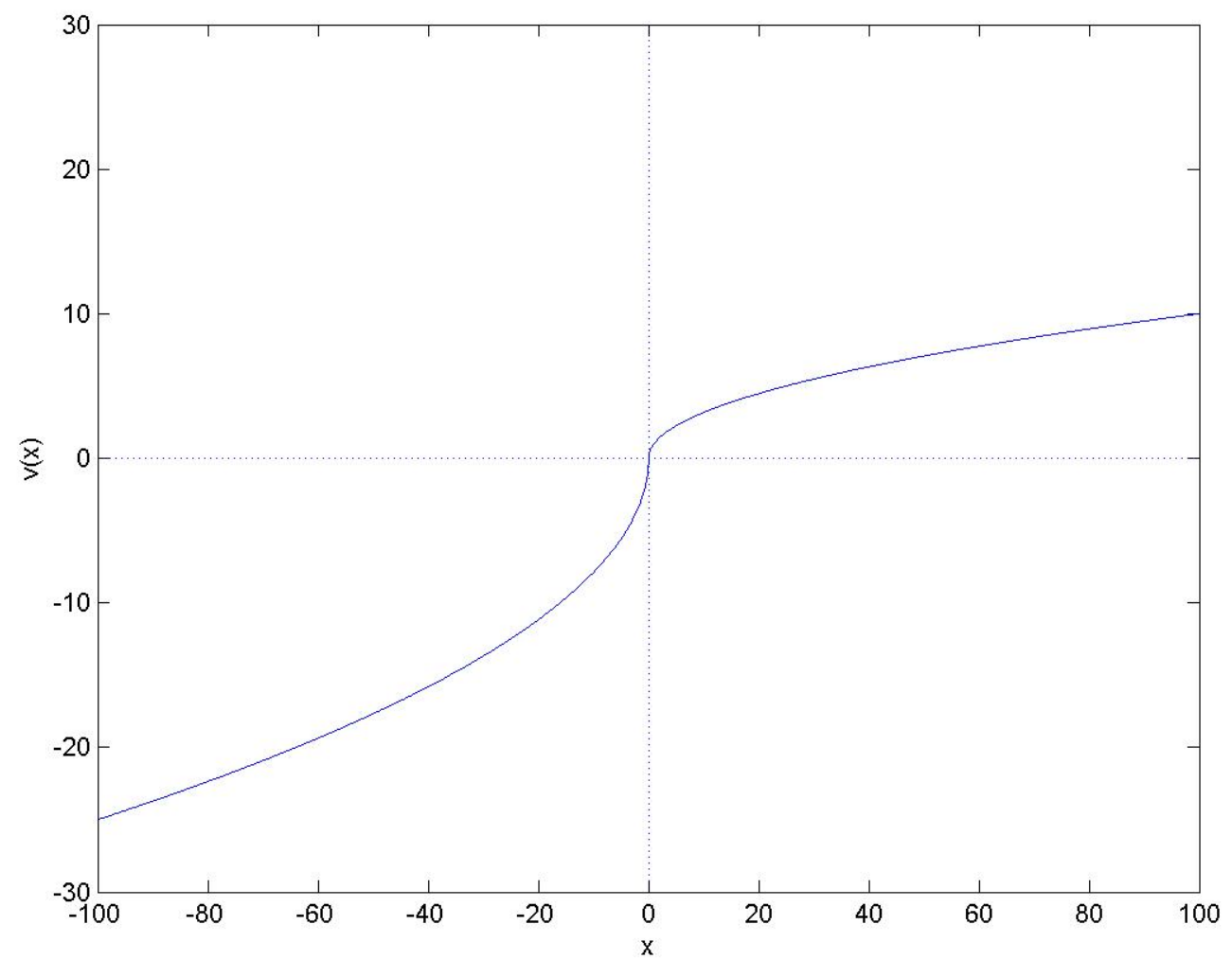

Figure 1

The Prospect Theory Value Function

Note: The graph plots the value function proposed by Tversky and Kahneman (1992) as part of cumulative prospect theory, namely $v(x)=x^{\alpha}$ for $x \geq 0$ and $v(x)=-\lambda(-x)^{\alpha}$ for $x<0$, where $x$ is a dollar gain or loss. The authors estimate $\alpha=0.88$ and $\lambda=2.25$ from experimental data. The plot uses $\alpha=0.5$ and $\lambda=2.5$ so as to make loss aversion and diminishing sensitivity easier to see. 


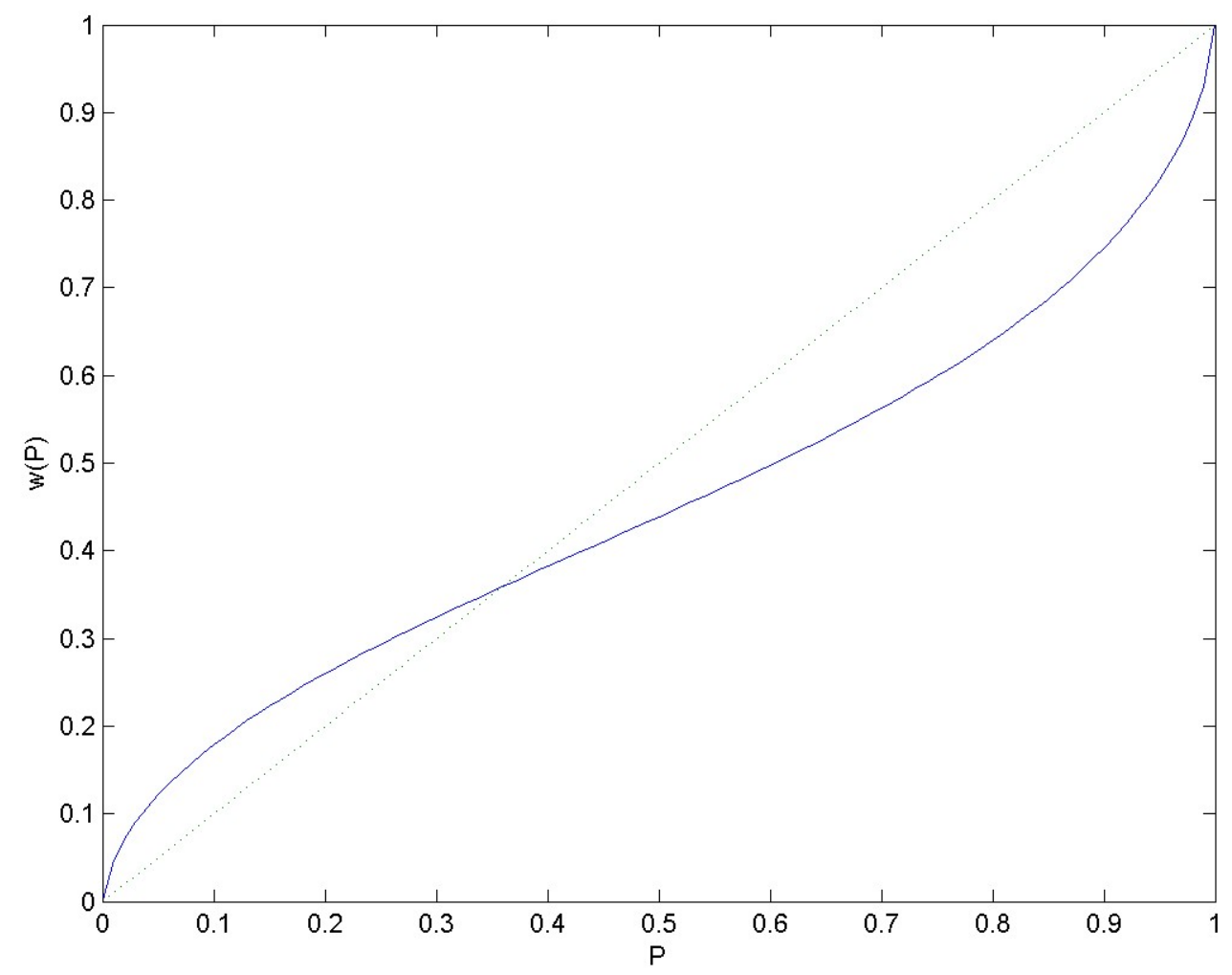

Figure 2

\section{The Probability Weighting Function}

Note: The graph plots the probability weighting function proposed by Tversky and Kahneman (1992) as part of cumulative prospect theory, namely $w(P)=P^{\delta} /\left(P^{\delta}+\right.$ $\left.(1-P)^{\delta}\right)^{1 / \delta}$, where $P$ is an objective probability, for two values of $\delta$. The solid line corresponds to $\delta=0.65$, the value estimated by the authors from experimental data. The dotted line corresponds to $\delta=1$, in other words, to linear probability weighting. 